\title{
ANTICANCER EFFECT AND IMMUNOLOGIC RESPONSE TO XENOGENEIC EMBRYONIC PROTEINS IN MICE BEARING EHRLICH SOLID CARCINOMA
}

\author{
T.V. Symchych*, N.I. Fedosova, O.M. Karaman, L.M. Yevstratieva, I.M. Voyeykova, H.P. Potebnia \\ R.E. Kavetsky Institute of Experimental Pathology, Oncologyand Radiobiology, NASof Ukraine, Kyiv 03022, Ukraine
}

Aim: To investigate anticancer and immunologic effects of chicken embryonic proteins (CEP) in mice bearing Ehrlich solid carcinoma. Materials and Methods: The study was carried out on male Balb/c mice bearing Ehrlich solid carcinoma. The immunizations were performed after the tumor transplantation. The immune status was assessed on days 7, 14, 21 and 28 after the tumor challenge. Cytotoxic activity (CAT) of macrophages (Mph), natural killer cells (NK), cytotoxic T-lymphocytes (CTL) and blood serum, as well as the influence of the blood serum on immune cells activity was checked in MTT-assay; Mph's cytochemical activity was tested in NBT-assay; Ehrlich antigen-specific or CEP-specific antibodies were detected in ELISA-assay; medium size circulating immune complexes (CIC) were detected in reaction of $4.5 \%$ polyethylene glycol precipitation. Results: The immunization resulted in tumor growth suppression and significant $25.64 \%$ prolongation of the survival time. In both control and immunized mice with transplanted tumors antibodies specific to Ehrlich carcinoma antigens and to CEP were detected, but antibody response was more balanced in the treatment group. In the treatment group both cytochemical and CAT of Mph was moderately activated and well preserved until late stages of tumor development; CAT of NK and CTL remained in the range of the intact mice until day 28 after the tumor transplantation. The immunized mice were well protected from accumulation of CIC and suppressive activity of autologous blood serum. Conclusion: Collectively, our data indicate that CEP can elicit immunomodulating and immunoprotecting effects sufficient to provide tumor growth inhibition. The further elaboration of a xenogeneic anticancer vaccine based on CEP is warranted.

Key Words: xenogeneic anticancer vaccine, chicken embryonic proteins, anticancer activity, Ehrlich carcinoma, immunologic effects.

Anticancer xenogeneic vaccine elaboration started after 1996 when Naftzger and coauthors showed that human gp75 could elicit antibodies (Abs) response to mouse gp75 in mice [1]. So, it was shown that xenogeneic homologous proteins can break immune tolerance to autologous cancer antigens ( $\mathrm{Ag})$, and stimulated xenogeneic anticancer vaccines development [2]. Some of these vaccines are already undergoing clinical trials [3].

As a source of xenogeneic Ag, chicken embryos are often utilized. Indeed, some proteins or genes of chicken origin when used as a xenogeneic vaccine showed an anticancer effect in case of different murine tumors models (Lewis lung carcinoma, murine $\mathrm{H} 22$ hepatoma, melanoma B-16, Meth A fibrosarcoma, CT26 colon adenocarcinoma) [4-7] and in an experimental canine transmissible venereal tumor model [8]. At R.E. Kavetsky Institute of Experimental Pathology, Oncology and Radiobiology of the NAS of Ukraine (IEPOR), the work is proceeding on elaboration of a xenogeneic vaccine based on chicken embryonic proteins (CEP). In previous experiments, its anticancer and antimetastatic effects were demonstrated on Lewis lung carcinoma model [9]. By the Guideline on the preclinical evaluation of medical products [10], the anticancer

Submitted: January 27, 2017.

*Correspondence: E-mail: immunomod@ukr.net Abbreviations used: Abs - antibodies; ADCA - antibody-dependent cytotoxic activity; Ag - antigen; BS - blood serum; CAT - cytotoxic activity; CATI - cytotoxic activity index; CEP - chicken embryonic proteins; CIC - circulating immune complexes; CTL - cytotoxic T-lymphocytes; EC - Ehrlich carcinoma; ILSP - index of life span prolongation; ITGI - index of tumor growth inhibition; MI - modulation index; Mph macrophages; NK - natural killer cells; OU - optical units. effect of preparation should be studied in 2-3 different tumor models. Consequently, the purpose of this work was to investigate anticancer and immunologic effects of CEP in mice bearing solid Ehrlich carcinoma (EC).

\section{MATERIALS AND METHODS}

The study has been carried out on 60 male Balb/c mice 2-2.5 month old weighting 20-21 g, bred at the vivarium of IEPOR (Kyiv, Ukraine). The use and care of experimental animals have been performed in accordance with standard international rules on biologic ethics and was approved by Institutional Animal Care and Use Committee [11].

To establish tumors, $4 \cdot 10^{5}$ cells/mouse of EC cells were injected i.m. into the right hind leg.

Tumor bearing mice $(n=26)$ were immunized on days 2, 5, and 8 after tumor cells transplantation. The immunization was performed s.c. with $0.3 \mathrm{ml}$ of CEP solution per mouse (protein concentration $0.3 \mathrm{mg} / \mathrm{ml}$ ). Nonimmunized tumor bearing mice $(n=26)$ were referred as nonimmunized control.

The CEP was prepared by extraction of 7-days chicken embryos with $0.9 \% \mathrm{NaCl}$ solution, containing $0.1 \%$ EDTA as described in [12]. The resulting supernatant was collected and frozen at $-20^{\circ} \mathrm{C}$.

Tumor dimensions were measured with calipers, and tumor volumes were calculated according to the formula:

tumor volume $=4 / 3 \pi \cdot$ width $^{2} \cdot$ length $\cdot 0,5$.

Index of Tumor Growth Inhibition (ITGI) was calculated according to the formula:

$I T G I=\left(\left(V_{\text {controlmice }}-V_{\text {immunized mice }}\right) / V_{\text {control mice })} \times 100 \%\right.$

where $V_{\text {control mice }}$ and $V_{\text {immunized mice }}$ stand for mean tumor volume in the control and immunized mice, respectively. 
Index of Life Span Prolongation (ILSP) was calculated as following:

$$
\text { ILSP }=((\text { survival time } \text { immunized mice }- \text { survival }
$$

time $_{\text {control mice }}$ / survival time control mice $\left._{\text {(ice }}\right) \cdot 100 \%$,

where survival time immunized mice and survival time $_{\text {control mice }}$ stand for mean survival time (days) in the immunized and control groups, respectively.

Immunological examination was performed on days 7, 14, 21 and 28 after the tumor transplantation. Data on the immunized mice $(n=12)$ were compared with nonimmunized tumor-bearing control $(n=12)$ and intact mice $(n=8)$ of the same strain, sex and age (is referred as the intact control).

Cytotoxic activity (CTA) of blood serum (BS), spleen lymphocytes and peritoneal macrophages (Mph) was determined by MTT-assay [13, 14]. K-562 cells were used as target cells for the examination of natural killer cell (NK) CAT, while EC cells were used as targets for cytotoxic T-lymphocytes (CTL), Mph and BS. In brief, target cells $\left(2 \cdot 10^{4} \mathrm{cell} /\right.$ well $)$ and immune cells $\left(1 \cdot 10^{5}\right.$ lymphocytes/well or $4 \cdot 10^{5} \mathrm{Mph} /$ well) were placed in a flat-bottom 96 -well plate and incubated for $18 \mathrm{~h}$ in a humidity atmosphere with $5 \% \mathrm{CO}_{2}$ at $37^{\circ} \mathrm{C}$. After that, $0.01 \mathrm{ml}$ of MTT solution/well $(5 \mathrm{mg} / \mathrm{ml}$, Sigma) was added, and incubation continued for $2 \mathrm{~h}$. Then the plates were centrifuged ( $1500 \mathrm{~g}$ for $15 \mathrm{~min}$ ) and washed twice with $0.9 \% \mathrm{NaCl}$ solution. After all, $0.12 \mathrm{ml}$ of $2 \mathrm{M} \mathrm{KOH}$ and $0.14 \mathrm{ml}$ of DMSO ( $50 \%$ solution) were added into the each well. Optical density was measured at $\lambda=545 \mathrm{~nm}$ vs $\lambda=630 \mathrm{~nm}$ with a micro ELISA reader (StatFax-2100, USA). Each sample was measured in triplicate.

Cytotoxic Activity Index (CTAl, \%) was calculated by the formula:

$C T A I=\left[1-\left(O D_{i c+t c}-O D_{i c}\right) /\left(O D_{t c}-O D_{\text {blank }}\right)\right] \cdot 100 \%$,

where $O D_{\text {ic }}-$ optical density of wells in which only immune cells were incubated; $O D_{t c}-$ optical density of wells in which only target cells were incubated; $\mathrm{OD}_{\mathrm{ic}+\mathrm{tc}}$ - optical density of wells in which tumor and immune cells where incubated; $O D_{\text {blank }}$ - optical density of wells with the culture medium only.

In order to determine BS effect on immune cells' CAT, $0.01 \mathrm{ml}$ of autologous BS was added to "target + immune cells" containing wells. All the other steps were the same as is described above.

Cytochemical activity of Mph (spontaneous and induced with pyrogenal) was studied in NBTassay [15]. In brief, Mph ( $1 \cdot 10^{6} \mathrm{cell} / \mathrm{ml}, 0.2 \mathrm{ml} /$ well $)$ were incubated with $0.02 \mathrm{ml} /$ well $0.2 \%$ NBT solution (Sigma, USA). To induce cytochemical activity, $0.013 \mathrm{ml} /$ well of pyrogenal $(100 \mathrm{mkg} / \mathrm{ml}$, Medhamal, RF) was used. After incubation $\left(1 \mathrm{~h}, 5 \% \mathrm{CO}_{2}, 37^{\circ} \mathrm{C}\right)$, the plates were washed twice with $0.9 \% \mathrm{NaCl}$ solution. $2 \mathrm{M} \mathrm{KOH}$ solution (0.06 ml/well) and $50 \%$ DMSO solution $(0.07 \mathrm{ml} /$ well) were used to dissolve diformazan granules. Optical density was measured at $\lambda=630 \mathrm{~nm}$ with the use of micro ELISA reader (StatFax-2100, USA). Each sample was measured in triplicate. The results are presented as optical units $(\mathrm{OU})$.

Activation Index (Al) was calculated as following:

$$
A I=O U_{(\text {induced test) }} / O U_{(\text {spontaneous test) }}
$$

where $\mathrm{OU}_{\text {(induced test) }}$ and $\mathrm{OU}_{\text {(spontaneous test) }}$ stand for optical units of wells with pyrogenal treated and untreated Mph respectively.

Circulating immune complexes (CIC) in BS of the mice were detected in reaction of $4.5 \%$ polyethylene glycol (PEG) precipitation [16]. Optical density was measured at $\lambda=450 \mathrm{~nm}$ with the use of micro ELISA reader (StatFax-2100, USA), and the data are presented as reference unit:

$$
R U_{(C I C)}=\left(O U_{P E G \text { well }}-O U_{\text {control well }}\right) \cdot 100 \text {, }
$$

where $\mathrm{OU}_{\text {control well }}$ and $\mathrm{OU} \mathrm{UEG}_{\mathrm{PE} \text { well }}$ stand for, respectively, optical density of control (BS + BBS buffer) and test (BS +4.5\% PEG in BBS buffer) wells.

CEP- or EC-Ag-specific IgG have been detected in an enzyme-linked immunosorbent assay (ELISA) as described earlier [17]. Briefly, the $0.1 \mathrm{ml}$ of CEP or EC-Ag solution $(0.3 \mathrm{mg} / \mathrm{ml})$ were incubated for $24 \mathrm{~h}$ at $4{ }^{\circ} \mathrm{C}$ on 96 -cells microtiter plates (Dynatech, Sweden). Nonspecific binding was blocked with 3\% BSA for $1 \mathrm{~h}$ at $37^{\circ} \mathrm{C}$. Sera were added at dilution 1:20. Bound Abs were revealed using goat antimouse IgG peroxidase conjugate (Sigma, USA) and o-phenyldiamine/ $\mathrm{H}_{2} \mathrm{O}_{2}$ substrates. Reaction was stopped by addition of $0.05 \mathrm{ml} /$ well $1 \mathrm{~mole} /$ liter $\mathrm{H}_{2} \mathrm{SO}_{4}$ solution. Plates were read at $492 \mathrm{~nm}$ in MicroELISA (StatFax-2100, USA) plate reader. The $B S$ of naive mice of the same strain, age and sex was used as the negative control. The results are presented as reference unit [18]:

$$
R U_{\text {(ELISA) }}=O D_{\text {experiment }} / O D_{\text {intact control, }}
$$

where $\mathrm{OD}_{\text {experiment }}$ stands for optical density of cells with $\mathrm{BS}$ of experimental tumor-bearing mice, $\mathrm{OD}_{\text {intact }}$ control stands for optical density of cells with naïve mice serum. The $R U_{\text {(ELSA) }}$ value exceeded 2 was taken as indication of Ab-positive serum.

In some cases, Modulation Index (MI) was calculated for better illustration of the differences between the control and experimental groups:

$M I=\left[C T A l_{\text {experiment }}-C T A I_{\text {control }} / C T A l_{\text {control }}\right] \cdot 100 \%$,

where CTAl experiment - index CTA for the group of experimental tumor-bearing animals; $\mathrm{CTAl}_{\text {control }}$ - index CTA for the group of intact mice of the same strain, age and sex.

The statistical analysis was made using Student $t$-test. The difference was considered significant at $p<0.05 ; 0.05<p<0.1$ was considered to represent a tendency. Correlation analysis was performed using Pearson correlation coefficient adjusted to the sample size.

\section{RESULTS}

All the mice of the control and treatment groups developed EC tumor on day 5-7 after the tumor cell transplantation (Table 1).

Table 1. Latent period of tumor development and mean survival time in mice bearing Ehrlich solid carcinoma

\begin{tabular}{cccc}
\hline Group & $\begin{array}{c}\text { Latent period of tumor } \\
\text { development, days }\end{array}$ & $\begin{array}{c}\text { Mean survival } \\
\text { time, days }\end{array}$ & $\begin{array}{c}\text { Median survi- } \\
\text { val time, days }\end{array}$ \\
\hline Nonimmunized $(n=14)$ & $5.5 \pm 0.34$ & $43.77 \pm 2.35$ & 44 \\
CEP immunized $(n=14)$ & $6.36 \pm 0.78$ & $58.86 \pm 4.09^{*}$ & 55 \\
\hline
\end{tabular}

Note: ${ }^{*} p<0.05$ compared to the control nonimmunized group. 
Starting from day 13 after the tumor transplantation, significant difference $(p<0.05)$ in tumor volume of the control and immunized animals become evident (Fig. 1). To illustrate, on days 13 and 16 after the tumor challenge ITGI reached 50.57 and $50.74 \%$, respectively. Since day 20 , ITGI started to gradually decline (46.11 and $43.27 \%$ on days 20 and 23 , respectively), but remained higher than $25 \%$ until the control mice began to die. Due to the tumor growth inhibition, the mean survival time of the immunized mice was $25.64 \%$ longer $(p<0.05)$ than that of the control mice (see Table 1).

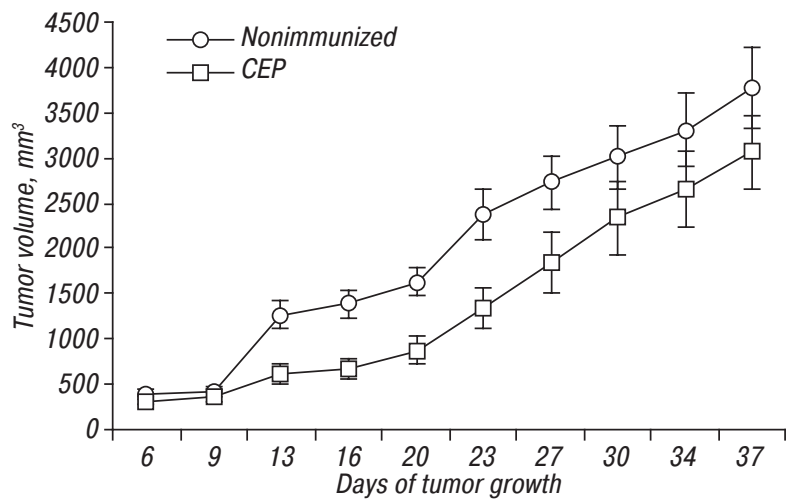

Fig. 1. Tumor growth kinetics in mice bearing Ehrlich solid carcinoma (CEP immunized and nonimmunized ones)

So, mice immunized with CEP showed tumor growth inhibition and life time prolongation. To address the issue of immune effects of CEP immunization we carried out an immunological examination of the treated and control mice. The mice were challenged with EC; on days 2, 5, and 8 after the tumor cells injection, the mice of the treatment group were immunized with CEP. The immunological examination of the animals was performed on days 7, 14, 21 and 28 after the tumor transplantation.

In the group of control tumor bearing mice, spontaneous cytochemical activity of Mph was almost the same as in the group of intact mice, except on day 28 of the experiment when it decreased and was significantly lower than that in the intact control group (Table 2). Although induced cytochemical activity of Mph in the control group was suppressed during almost entire time of investigation (on days 7 and $28 p<0.05$ compared to the intact control).

Table 2. Mph cytochemical activity in mice bearing Ehrlich solid carcinoma (CEP immunized, nonimmunized, and intact ones)

\begin{tabular}{|c|c|c|c|c|}
\hline \multirow[b]{2}{*}{ Group } & \multirow{2}{*}{$\begin{array}{l}\text { Day of } \\
\text { tumor } \\
\text { growth }\end{array}$} & \multicolumn{2}{|c|}{ Cytochemical activity, OU } & \multirow[b]{2}{*}{$\begin{array}{l}\text { Activation in- } \\
\quad \text { dex, } \%\end{array}$} \\
\hline & & Spontaneous & $\begin{array}{l}\text { Induced with } \\
\text { pirogenal }\end{array}$ & \\
\hline $\begin{array}{l}\text { Intact con- } \\
\text { trol }(n=8)\end{array}$ & 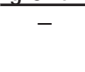 & 0 & $0.681 \pm 0.043$ & .005 \\
\hline $\begin{array}{l}\text { Nonimmu- } \\
\text { nized } \\
(n=12)\end{array}$ & $\begin{array}{c}7 \\
14 \\
21 \\
21 \\
28\end{array}$ & $\begin{array}{l}0.823 \pm 0.075 \\
0.683 \pm 0.018 \\
0.718 \pm 0.047\end{array}$ & $\begin{array}{l}0.795 \pm 0.082 \\
0.708 \pm 0.018 \\
0.710 \pm 0.057\end{array}$ & $\begin{array}{l}0.966 \pm 0.012^{1} \\
1.037 \pm 0.049 \\
0.987 \pm 0.020\end{array}$ \\
\hline $\begin{array}{l}\text { CEP immu- } \\
\text { nized } \\
(n=12)\end{array}$ & $\begin{array}{c}28 \\
7 \\
14 \\
21 \\
28\end{array}$ & $\begin{array}{l}0.616 \pm 0.006^{5} \\
0.814 \pm 0.022^{1} \\
0.660 \pm 0.028^{4} \\
0.643 \pm 0.023^{4} \\
0.661 \pm 0.035^{4}\end{array}$ & $\begin{array}{c}0.580 \pm 0.012^{1 *, 3,5} 5.5 \\
0.820 \pm 0.036^{1^{*}} \\
0.684 \pm 0.023^{4} \\
0.647 \pm 0.047^{4} \\
0.631 \pm 0.013^{4}\end{array}$ & $\begin{array}{c}0.942 \pm 0.020^{1} \\
1.007 \pm 0.017 \\
1.038 \pm 0.046 \\
1.006 \pm 0.033 \\
0.955 \pm 0.021^{1 *}\end{array}$ \\
\hline
\end{tabular}

Note: ${ }^{1} p<0.05$ compared to intact control; ${ }^{1 *} 0.05<p<0.1$ compared to intact control; ${ }^{2} p<0.05$ compared to tumor-bearing control; ${ }^{3} p<0.05$ compared to CEP; ${ }^{4} p<0.05$ compared to data obtained on day 7 in the same group; ${ }^{5} p<0.05$ compared to all the previous days of investigation in the same group.
Mph cytochemical activity of the immunized mice showed a different pattern. The highest activity was documented on day 7 ( $p<0.05$ compared to the intact control); thereafter it has slightly decreased but never has fallen below the normal range. Induced cytochemical activity in this group remained unchanged until day 28 of experiment, when a slight decrease was documented ( $p<0.07$ compared to the intact control). In other words, in the treated group of mice, contrary to the control group, cytochemical activity of Mph was well preserved until the late stages of the tumor development.

The difference between Mph CAT in the two groups was even more evident (Table 3 ). For instance, CAT of Mph in the control group was lower than that in the intact control group $(p<0.05$ on days 14 and 28). Autologous BS, when added to Mph and target cells, was not able to change the pattern, but weakened it even more (especially on days 21 and 28 of tumor growth). To illustrate, BS added to Mph and target cells on day 21 led to sharp decrease of $37.62 \%$ in Mph CAT (compared to Mph CAT without BS). On 28 day after the tumor transplantation, addition of autologous BS totally abrogated Mph CAT in 2 out of 3 mice. The last mouse's CATI was very low and made up only $2.58 \%$.

Contrary to the control tumor-bearing group, Mph CAT in the treatment group was slightly increased over the entire experiment $(p<0.05$ on day 7 compared to the intact control, on days 14 and 28 compared to the tumor-bearing control). Autologous BS added to Mph did not change its CAT significantly, except day 28, when it caused evident decrease of Mph CTA $(p<0.05$ compared to the intact control and all the previous time points). However, it remained by 3.97 times higher than that in the control group.

Table 3. CAT of Mph in mice bearing Ehrlich solid carcinoma (CEP immunized and nonimmunized) and intact animals

\begin{tabular}{lccccc}
\hline \multirow{2}{*}{ Group } & CAT & \multicolumn{4}{c}{ Day of tumor growth } \\
\cline { 3 - 6 } & index $\%$ & 7 & \multicolumn{4}{c}{14} & 21 \\
\hline Intact con- & Mph & \multicolumn{4}{c}{$23.04 \pm 1.29$} \\
trol $(\mathrm{n}=8$ ) & Mph + BS & \multicolumn{4}{c}{$22.17 \pm 0.71$} \\
Nonimmu- & Mph & $24.10 \pm$ & $16.19 \pm$ & $18.91 \pm$ & $14.78 \pm$ \\
nized & & 1.74 & $1.40^{1,3}$ & 2.72 & $0.77^{1,3}$ \\
( $\mathrm{n}=12)$ & Mph + BS & $26.19 \pm$ & $17.42 \pm$ & $12.88 \pm$ & 2.58 (one \\
& & 1.87 & $3.47^{1,3}$ & $4.27^{1,3}$ & mice) \\
CEP immu- & Mph & $27.72 \pm$ & $26.54 \pm$ & $25.88 \pm$ & $28.99 \pm$ \\
nized & & $0.66^{1}$ & $2.21^{2}$ & 3.18 & $4.69^{2}$ \\
( $\mathrm{n}=12)$ & \multirow{2}{*}{ Mph + BS } & $29.62 \pm$ & $26.52 \pm$ & $22.25 \pm$ & $10.23 \pm$ \\
& & $0.65^{1}$ & 3.80 & 3.84 & $4.17^{1,4}$ \\
\hline
\end{tabular}

Note: ${ }^{1} p<0.05$ compared to intact control; ${ }^{2} p<0.05$ compared to tumor-bearing control; ${ }^{3} p<0.05$ compared to data obtained on day 7 in the same group; ${ }^{4} p<0.05$ compared to all the previous time points in the same group.

When the data are presented in $\mathrm{Ml}$, the difference between the two groups is even more evident (Fig. 2). As compared to intact control, the MI of Mph CAT in the CEP group was positive over the entire experiment, $\mathrm{Ml}$ of Mph + BS CAT turned into negative only at the last observation point. While in the control tumor-bearing group Mls of both Mph and Mph + BS activity were negative starting day 14 of tumor growth. Depending on the observation time point, 
MI was equivalent $-17.93 \% \ldots-35.85 \%$ in the case of direct Mph CAT and $-21.43 \% \ldots-88.36 \%$ for Mph + BS CAT.
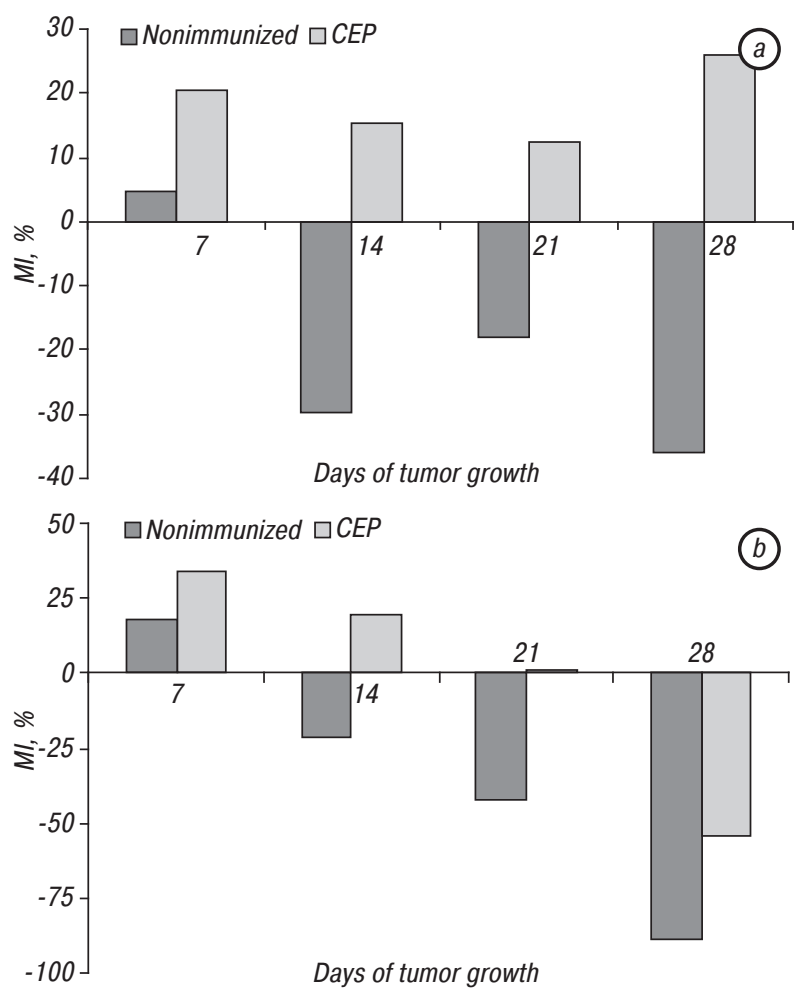

Fig. 2. MI as compared to intact control of direct (a) and BS dependent $(b)$ Mph CAT in mice bearing Ehrlich solid carcinoma (CEP immunized and nonimmunized)

The NK CTA of control and immunized mice is depicted in Fig. 3. As one may see, the NK CTA of immunized mice did not differ significantly from the data of the intact control group throughout the entire experiment. While in the control group it sharply decreased on day 28 ( $p<0.05$ comparing with days 7 and 14 of tumor growth) and was significantly lower than that in the intact control (MI was equal $-60.98 \%$ ) and CEP (MI equal $-51.92 \%)$ groups.

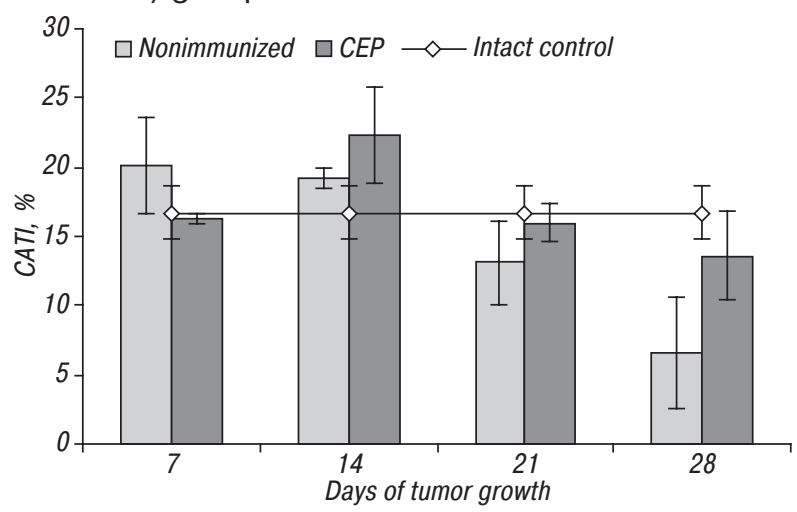

Fig. 3. CAT of NK in mice bearing Ehrlich solid carcinoma (CEP immunized and nonimmunized) and intact ones

The CAT of CTL in the control group of mice did not differ significantly (except the day 14) from the intact control level (Table 4). Antibody-dependent cytotoxic activity (ADCA) was lower than that in the intact control group $(p<0.05$ on day 21 , and $p<0.1$ on day 28 of the investigation). The Mls compared to the intact control group were $-31.31 \%$, $-41.29 \%$ and $-37.38 \%$ on days 14,21 and 28 , correspondingly.

The CTL CTA and ADCA of the immunized mice did not differ significantly from the intact control data. As compared to the nonimmunized tumor-bearing mice, the ADCA was slightly higher - Ml fluctuated between 10.73 and $30.13 \%$ depending on the day of tumor growth $(p<0.07$ and $p<0.05$ on days 7 and 28, correspondingly).

Table 4. CAT of T-lymphocytes and ADCA in mice bearing Ehrlich solid carcinoma (CEP immunized and nonimmunized) and intact onces

\begin{tabular}{|c|c|c|c|c|c|}
\hline \multirow{2}{*}{ Group } & \multirow{2}{*}{$\begin{array}{c}\text { CAT } \\
\text { index, } \\
\%\end{array}$} & \multicolumn{4}{|c|}{$\begin{array}{c}\text { Day } \\
\text { of tumor growth }\end{array}$} \\
\hline & & 7 & 14 & 21 & 28 \\
\hline \multirow{6}{*}{$\begin{array}{l}\text { Intact } \\
\text { control } \\
(n=8) \\
\text { Non- } \\
\text { immu- } \\
\text { nized } \\
(n=12) \\
\text { CEP im- } \\
\text { munized } \\
(n=12)\end{array}$} & \multirow{2}{*}{$\begin{array}{c}\mathrm{CTL} \\
\mathrm{ADCA}\end{array}$} & \multicolumn{4}{|c|}{$25.61 \pm 1.35$} \\
\hline & & \multicolumn{4}{|c|}{$25.55 \pm 5.53$} \\
\hline & $\begin{array}{l}\text { CTL } \\
\text { CTA }\end{array}$ & $27.96 \pm 1.69$ & $20.50 \pm 2.15^{1,3}$ & $23.48 \pm 0.87$ & $23.71 \pm 1.37$ \\
\hline & ADCA & $26.19 \pm 1.87$ & $17.55 \pm 1.08^{3}$ & $15.00 \pm 0.63^{1,3}$ & $16.00 \pm 1.90^{1 * 3}$ \\
\hline & $\begin{array}{l}\text { CTL } \\
\text { CTA }\end{array}$ & $23.63 \pm 5.43$ & $22.34 \pm 3.68$ & $24.99 \pm 0.49$ & $23.57 \pm 0.76$ \\
\hline & ADCA & $29.62 \pm 0.65^{2^{*}}$ & $20.69 \pm 5.22$ & $16.61 \pm 2.35$ & $20.82 \pm 0.33^{2,3}$ \\
\hline
\end{tabular}

Note: ${ }^{1} p<0.05$ compared to intact control; ${ }^{1 *} 0.05<p<0.1$ compared to intact control; ${ }^{2} p<0.05$ compared to tumor-bearing control; ${ }^{2 *} 0.05<p<$ 0.1 compared to tumor-bearing control; ${ }^{3} p<0.05$ compared to data obtained on day 7 in the same group.

The BS CTA (Fig. 4) of both immunized and nonimmunized mice did not differ significantly from the intact control data on the first two time points, but sharply increased on days 21 and 28 of the experiment ( $p<0.05$ in both cases for both groups). The difference in BS CTA of immunized and control tumorbearing mice was insignificant.

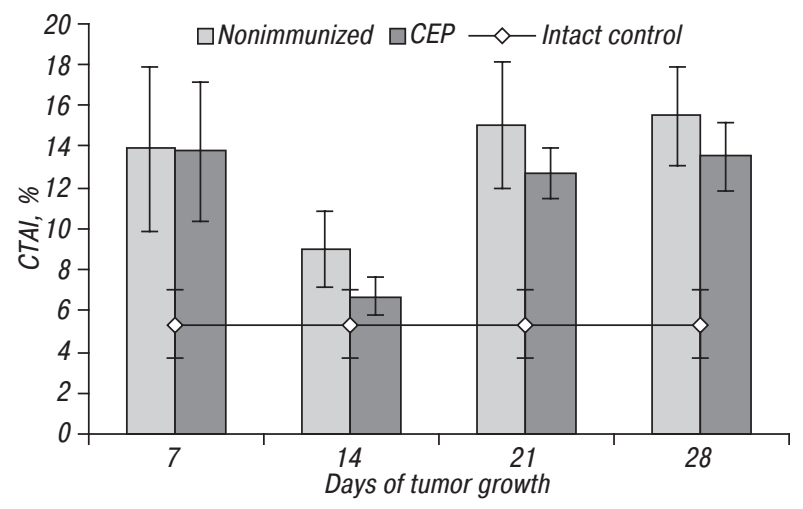

Fig. 4. BS CAT in mice bearing Ehrlich solid carcinoma (CEP immunized and nonimmunized) and intact ones

The mice of both control tumor-bearing and immunized groups produced EC-Ag- and CEP-specific Abs (Fig. 5, $a$ and 5, $b$ ). The percentage of control mice producing Abs specific to ether EC-Ag or CEP was almost stable over the experiment (except for sharp increase of CEP-specific positive mice on day 14 , $p<0.05$ as compared to days 7 and 21 ). In the group of the treated mice, the pattern was completely different. The percentage of EC-Ag or CEP-specific Abspositive mice was surprisingly low at day $7: 54.55$ and $50.00 \%$, respectively. Starting on day 14 the percentage of mice expressing Abs specific to EC-Ag or CEP 
have significantly increased $(p<0.05$ as compared to day 7 data for both Ags); on days 21 and 28 all the immunized mice were positive for both EC-Ag and CEPspecific Abs $(p<0.05$ as compared to day 7 for both Ags). Even more, on the last two observation points the percentages of Abs-positive mice (for both Ags) were significantly higher than that in the control group.

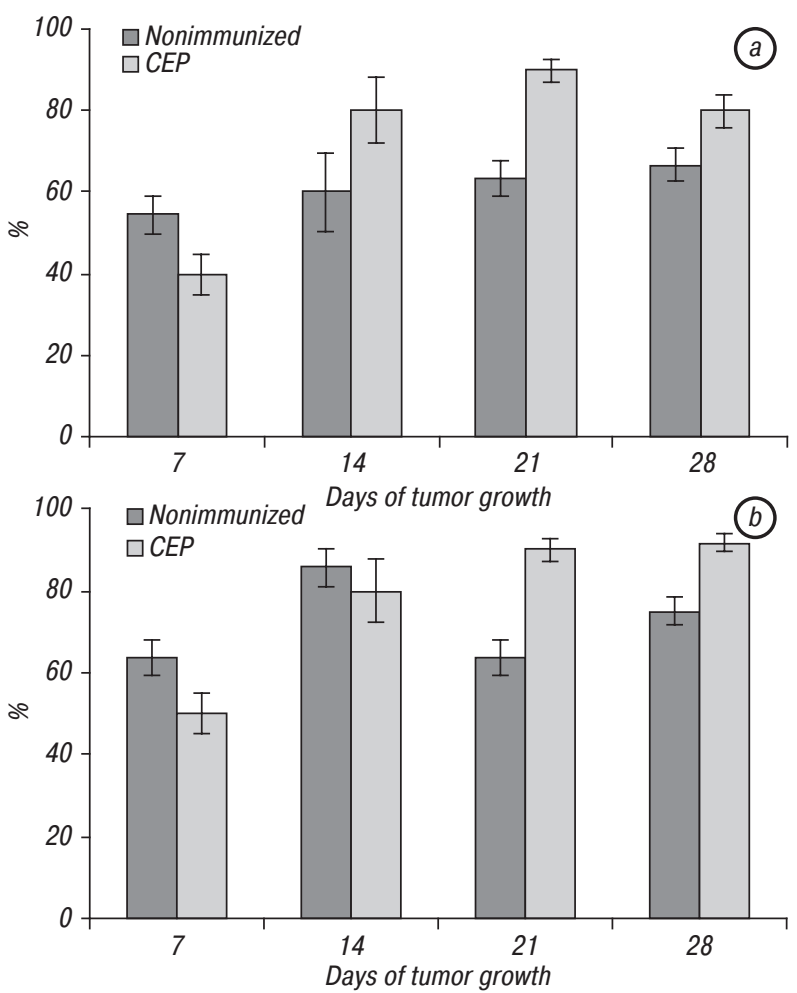

Fig. 5. Percentage of animals expressing EC-Ag specific (a) and CEP-specific (b) Abs in the groups of mice bearing Ehrlich solid carcinoma (CEP immunized and nonimmunized ones)

The level of either EC-Ag or CEP-specific Abs did not differ significantly over the experiment in the control group (Fig. 6, a). It just can be mentioned that on days 21 and 28 of the experiment the level of ECAg specific Abs was slightly higher than the level of CEP-specific Abs inside the group $(p<0.06$ and $p<0.07$, correspondingly). In the immunized group the level of Abs specific to EC-Ag was relatively stable over the experiment (except slight increase on day $21 ; p<0.06$ as compared with day-7 data). Although the level of CEP-specific Ab was continuously growing (compared to day $7, p<0.08$ on day 14 , $p<0.05$ on days 21 and 28; compared to day 14 , $p<0.05$ on day 28). On days 21 and 28 , the level of CEP-specific Ab was higher $(p<0.05$ and $p<0.07$, respectively) than that in the control group.

The level of medium size CIC in BS of the control tumor-bearing mice was gradually and stably growing over the experiment $(p<0.07$ on day 21 and $p<0.05$ on day 28 as compared to day 7 level), so on day 28 it was significantly higher than that in the intact control group (Fig. 7). In the group of immunized mice, the $\mathrm{CIC}$ level was changing but without significant differences as compared to both the intact and control tumor-bearing mice.

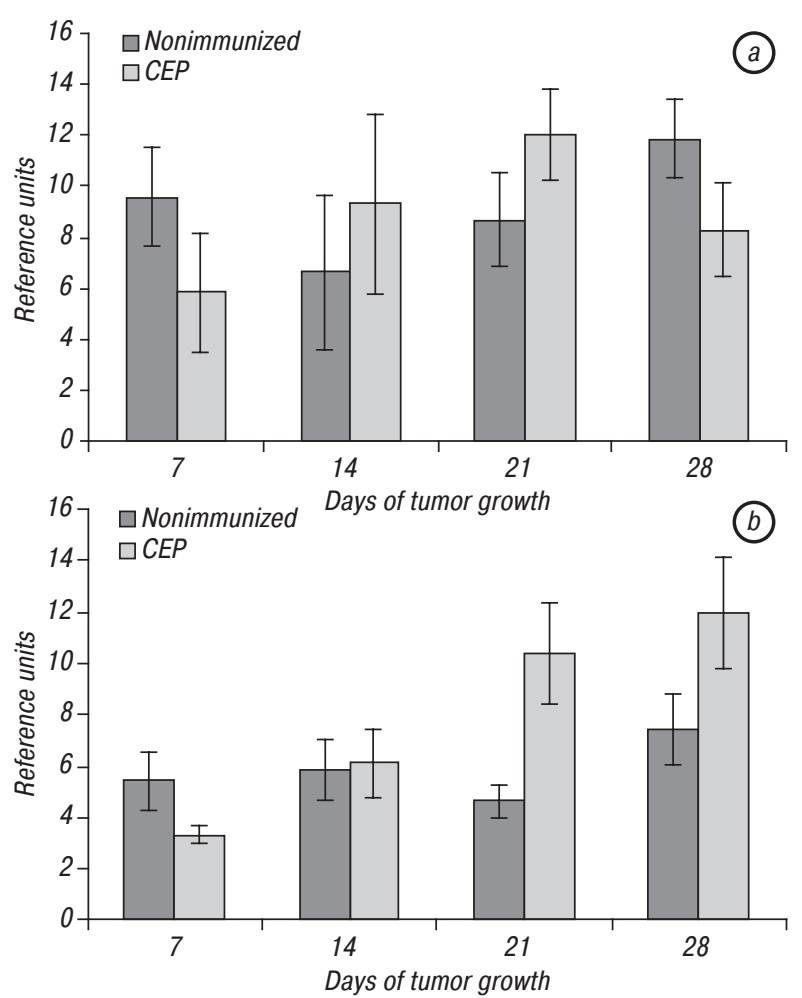

Fig. 6. Level of EC-Ag (a) or CEP (b) specific Abs in BS in mice bearing Ehrlich solid carcinoma (CEP immunized and nonimmunized ones)

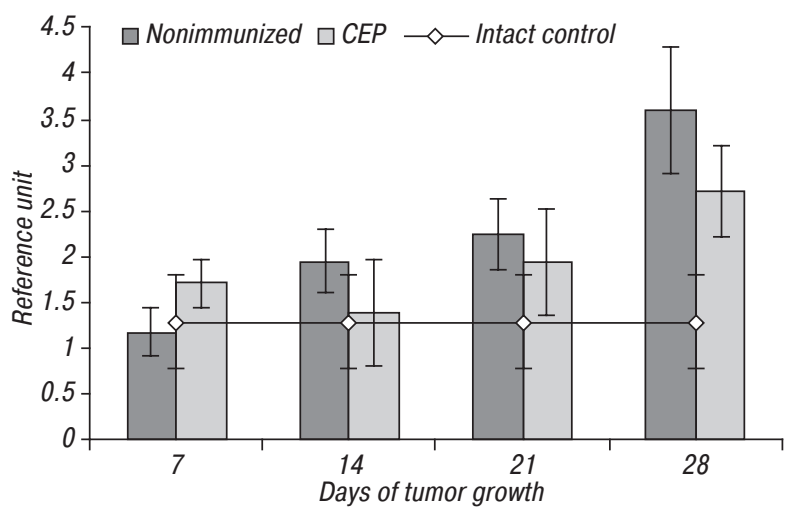

Fig. 7. Level of medium size CIC in BS in mice bearing Ehrlich solid carcinoma (CEP immunized and nonimmunized) and intact ones

\section{DISCUSSION}

So, we observed the inhibition of tumor growth in the group of immunized mice. The maximal ITGI reached 50.57 and $50.74 \%$ on days 13 and 16 after the tumor challenge (which corresponds to days 5 and 8 after the last immunization). The mean survival time of immunized mice was $25.64 \%$ longer $(p<0.05)$ than that of the control mice ( 58.86 days vs 43.77 ). We considered these effects sufficient to continue further investigations.

To unravel mechanisms that underlie the anticancer effect of CEP, immunological analysis of the immunized and control tumor-bearing mice has been carried out. It can be concluded that immunization with CEP did not elicit remarkable immune cell activation. On the other hand, the immunized mice showed fewer signs of immune system exhaustion and tumor-caused sup- 
pression. The protection effect is especially evident when it comes to activity of Mph (both cytotoxic and cytochemical) and NK.

Even more striking is difference in BS effects on immune cells of the treated and the control tumorbearing mice. For example, BS of immunized mice increased or did not affect CTA of Mph or lymphocytes, correspondingly. While in the control group of mice, BS led to significant reduction in Mph and lymphocytes activities. The CIC increase can be assumed at least as one of causes which lead to inhibitory activity of BS, as long as CIC are well known as so called "blocking factors" and may unfavorably affect the immunity of tumor-bearing hosts [19] by modulating cellular and humoral immune responses through interaction with NK, Mph, B- and T-lymphocytes [20]. Indeed, in the control group correlation between tumor volume and the level of CIC was positive $(r=0.63,95 \%$ $\mathrm{Cl} 0.85-0.22, p<0.02$ ), whereas correlation between CIC level and Mph CTA (both with and without BS) was negative: $r=-0.71(95 \% \mathrm{Cl}-0.07 \ldots-0.93, p<0.03)$ and $r=-0.69(95 \% \mathrm{Cl}-0.08 \ldots-0.91, p<0.03)$. On the other hand, in the group of immunized mice no statistically significant correlation has been found. So, it looks as if immunization with CEP prevented excessive CIC generation/accumulation or enforced CIC elimination.

Neither immunized nor control mice elicited anticancer CTL response, but a large percentage of mice of both control and treatment groups expressed EC$\mathrm{Ag}$ and/or CEP-specific Abs. The last fact matches with another report that Balb/c mice are prone to Th2 type immune response rather than to Th1 [21].

The role of humoral immune response in anticancer defense is still debatable, and is often considered rather negative than positive [22-27]. Taking this into consideration, the correlation analysis between the level of ether EC-Ag or CEP-specific Abs and the immune effectors' CTA was carried out. In the control group of mice, there was strong negative correlation between the level of EC-Ag specific Abs and NK CAT $(r=-0.65,95 \% \mathrm{Cl}-0.04 \ldots-0.92, p=0.037)$ but strong positive correlation between EC-Ag specific Abs and BS CAT ( $r=0.57,95 \% \mathrm{Cl} 0.10-0.93, p=0.026)$. In the group of immunized mice, the level of EC-Ag specific Abs had negative correlation with lymphocytes ADCA $(r=-0.65,95 \% \mathrm{Cl}-0.94 \ldots 0.12, p=0.046)$.

In the control group, the level of CEP-specific Abs showed strong negative correlation with NK CAT ( $r=-0.66,95 \% \mathrm{Cl}-0.92 \ldots-0.05, p=0.037)$, lymphocyte ADCA $(r=-0.78,95 \% \mathrm{Cl}-0.95 \ldots-0.3, p=0.01)$ and BS-dependent Mph CAT $(r=-0.63,95 \% \mathrm{Cl}-0.92 \ldots$ $0.01, p=0.056)$. In the treatment group, the concentration of CEP-specific Ab correlated inversely with lymphocyte ADCA $(r=-0.75,95 \% \mathrm{Cl}-0.08 \ldots-0.96$, $p=0.046$ ) only. What is the reason that almost the same concentration of Abs in different groups of mice had different relations with immune cells' activity? It is very likely that the mice of the treatment group expressed Abs specific to other Ag than that in the control group. Both CEP and EC-Ag are rough tissue extracts consist- ing of a large number of $\mathrm{Ag}$. So, in the ELISA the same OD could be generated due to high concentration of Abs specific to just one $\mathrm{Ag}$, or due to the summation of low concentrations of Abs specific to two or more distinct Ags. Other than ELISA techniques (for instance Western blotting) would solve this issue. The answer may be helpful in the case of CEP-based vaccine purification and standardization.

It is very interesting that in the control group the level of CEP-specific Abs correlated strongly with the level of EC-Ag specific Abs ( $r=0.816,95 \% \mathrm{Cl} 0.56-0.93$, $p=0.0002$, while in the immunized group this relations is less evident $(r=0.51,95 \% \mathrm{Cl} 0.02-0.8, p=$ 0.039 ). These findings allow us to assume that CEP and EC-Ag share some similar epitops or Ags, as long as it looks like the presence of CEP-specific Abs in the control group is due to the cross-reaction of the ECAg specific Abs. While in the immunized group, factors other than just cross-reacting EC-Ag specific Abs affect the induction and the level of CEP-specific Abs.

In conclusion, the tumor-bearing mice of the control and immunized groups showed induction of humoral immune response. However, in the group of immunized mice the response was more balanced: contrary to the control mice, autologous BS increased or at least did nod suppress CAT of Mph or lymphocytes, medium size $\mathrm{CIC}$ did not increase significantly, and Abs interfere with the only one immune cells' reaction (to compare, in the control group were three negative relations). Moreover, the immunization elicited moderate activation of cellular immune response and preserved its functioning until the late stage of tumor growth. All together, these effects led to the tumor growth suppression and survival time prolongation. The further elaboration of a xenogeneic anticancer vaccine based on CEP is warranted.

\section{CONCLUSION}

Application of the CEP to Ehrlich solid carcinoma bearing mice results in suppressed tumor growth and significantly prolonged survival time. Applied under the therapeutic scheme, CEP had modulating and protecting effects on the immune system of EC bearing mice. The most notable effects are the induction of balanced Abs response, the preserving of CAT of Mph and lymphocytes, balancing the medium size $\mathrm{CIC}$ level and converting from negative to positive influence of BS on activity of immune cells.

\section{REFERENCES}

1. Naftzger C, Takechi $\mathrm{Y}$, Kohda H, et al. Immune response to a differentiation antigen induced by altered antigen: a study of tumor rejection and autoimmunity. Proc Natl Acad Sci USA 1996; 93: 14809-14.

2. Cavallo F, Aurisicchio L, Mancini R, Ciliberto G. Xenogene vaccination in the therapy of cancer. Expert Opin Biol Ther 2014; 14: 1427-42.

3. Strioga MM, Darinskas A, Pasukoniene V, et al. Xenogeneic therapeutic cancer vaccines as breakers of immune tolerance for clinical application: To use or not to use? Vaccine 2014; 32: 4015-24. 
4. Luo Y, Wen YJ, Ding ZhY, et al. Immunotherapy of tumors with protein vaccine based on chicken homologous Tie-2. Clin Cancer Res 2006; 12: 1813-9.

5. Su J-M, Wei Y-Q, Tian L, et al. Active immunogene therapy of cancer with vaccine on the basis of chicken homologous matrix metalloproteinase-2. Cancer Res 2003; 63: 600-7.

6. Yi T, Wei Y-Q, Tian L, et al. Humoral and cellular immunity induced by tumor cell vaccine based on the chicken xenogeneic homologous matrix metalloproteinase-2. Cancer Gene Therapy 2007; 14: 158-64.

7. Shaoping ZH, Junzhi ZH, Shaojiang ZH, et al. Antiangiogeneic target therapy for cancer with vaccine based on the recombinant chicken FGFR-1 in tumor-bearing mice. J Huazhong Univ Sci Technolog Med Sci 2007; 27: 120-3.

8. Yu W-Y, Chuang T-F, Guichard C, et al. Chicken HSP70 DNA vaccine inhibits tumor growth in a canine cancer model. Vaccine 2011; 29: 3489-500.

9. Symchych TV, Fedosova NI, Karaman OM, et al. Anticancer effectiveness of vaccination based on xenogeneic embryo proteins applied in different schedules. Exp Oncol 2015; 37: 1-6.

10. Preclinical study of medical products. Guideline. OV Stephanov, ed. Kyiv: Avicena, 2001: 361-71 (in Ukrainian).

11. Kozhemyakin YuM, Kchromov OS, Filonenko MA, et al. Guideline on management of laboratory animals and work with them. Kyiv, 2002. 179 p. (in Ukrainian).

12. Isokawa $K$, Rezaee $M$, Wunsch $A$, et al. Identification of transferrin as one of multiple EDTA-extractable extracellular proteins involved early chick heart morphogenesis. J Cell Biochem 1994; 54: 207-18.

13. Ohno M, Abe T. Rapid colorimetric assay for the quantification of leukemia inhibitory factor (LIF) and interleukin-6 (IL-6). J Immunol Methods 1991; 145: 199-203.

14. Mosmann T. Rapid colorimetric assay for cellular growth and survival: application to proliferation and cytotoxicity assays. J Immunol Methods 1983; 65: 55-63.

15. Basics of clinical immunology and methodological approach to immune status evaluation: Manuals. AH Goncharov, ES Frejdlin, VS Cmirnov, et al. Gen ed by MH Romancov. Kaliningrad: Kaliningrad Univ, 1997: 51 (in Russian).

16. Immune status, basics to its assessment and corrections of immune disorders. VH Perederiy, AM Zemskov, NG Bychkova, VM Zemskov. Kiev, 1995: 61-2 (in Russian).
17. Autenshlius AI, Ivanova OV, Gauzer VV, Cemernikov VA. Antibody to Bacillus megaterium $H$. glycoprotein in pregnant women with a pathological course of pregnancy. Bull Exp Biol Med 1995; 120: 203-6 (in Russian).

18. Theory and practice of immunoassay. AM Egorov, AP Osipov, BB Dzantiev, EM Gavrilova, eds. M: Higher School, 1991. 288 p. (in Russian).

19. Guy K, Di Mariot U, Irvinet WJ, et al. Circulating immune complexes and autoantibodies in lung cancer. Br J Cancer 1981; 43: 276-83.

20. Salinas FA, Wee KH, Silver HK. Immune complexes and human cancer. Contemporary topics in Immunobiology. Vol 15. FA Salinas, MG Hanna, eds. New York: Plenum Press, 1985: 55-8.

21. Kuroda E, Yamashita U. Mechanisms of enhanced macrophage-mediated prostaglandin E2 production and its suppressive role in Th1 activation in Th2-dominant BALB/c mice. J Immunol 2003; 170: 757-64.

22. Mohammed ZM, Going JJ, Edwards J, et al. The relationship between lymphocyte subsets and clinico-pathological determinants of survival in patients with primary operable invasive ductal breast cancer. Br J Cancer 2013; 109: 1676-84.

23. Angelopoulou K, Rosen B, Stratis M, et al. Circulating antibodies against $\mathrm{p} 53$ protein in patients with ovarian carcinoma. Correlation with clinicopathologic features and survival. Cancer 1996; 78: 2146-52.

24. Olkhanud PB, Damdinsuren B, Bodogai M, et al. Tumor-evoked regulatory B cells promote breast cancer metastasis by converting resting $\mathrm{CD}^{4+} \mathrm{T}$ cells to $\mathrm{T}$-regulatory cells. Cancer Res 2011; 71: 3505-15.

25. Fremd C, Schuetz F, Sohn Ch, et al. B cell-regulated immune responses in tumor models and cancer patients. Oncoimmunol 2013; 2: e25443 (https://www.ncbi.nlm.nih.gov/ pmc/articles/PMC3782133/pdf/onci-2-e25443.pdf).

26. Bodoor K, Matalka I, Hayajneh R, et al. Evaluation of BCL-6, CD10, CD138 and MUM-1 expression in diffuse large B-cell lymphoma patients: CD138 is a marker of poor prognosis. Asian Pac J Cancer Prev 2012; 13: 3037-46.

27. Lundgren S, Berntsson J, Nodin B, et al. Prognostic impact of tumour-associated B cells and plasma cells in epithelial ovarian cancer. J Ovarian Res 2016; 9 (https://www.ncbi.nlm.nih.gov/ pmc/articles/PMC4822228/pdf/13048_2016_Article_232.pdf). 